skin. Williams et al. (1960) quote several studies in which it was shown that the wound sepsis rate was higher in patients who were nasal carriers.

Adequate skin-cleansing with antibacterial agents may sterilize the skin surface, but organisms exuded from sweat and sebaceous glands may in tirne contaminate porous skin towels and the wound. Only careful exclusion of the patient's skin surface will prevent this route of entry. Lowbury and Lilly (1960) have shown that preparation of the skin with antiseptics may reduce the number of bacteria but not eliminate them completely. It is therefore important to attempt to protect the wound from the entry of organisms from the surrounding skin even though it may have been thoroughly prepared.

While we do not deny that wounds may be infected from many sources within and without the theatre, demonstration of the route and source of specific infections is most difficult. All possible sources of organisms should therefore be eradicated or excluded. This paper focuses attention chiefly on one source, one that is often neglected-the patient himself at operation.

\section{Summary and Conclusions}

New techniques of skin preparation and skin towelling were introduced into the Surgical Professorial Unit at St. Thomas's Hospital in January, 1959. In the ensuing three years a fall in wound sepsis rate was observed compared with the previous four years.

It is suggested that one of the important sources of organisms infecting surgical wounds may be the patient's own skin. Good exclusion of the skin surface from the wound can be obtained with modern methods.

We are grateful to Professor R. Hare and Professor R. A. Shooter for help and suggestions during this work, and to Mr. M. P. Curwen, of the Department of Medical Statistics of St. Bartholomew's Hospital, for his advice.

REFERENCES

Hare, R., and Ridley, M. (1958). Brit. med. J., 1, 69 Kinmonth, J. B., Hare, R., Tracy, G. D., Thomas, C. G. A., Marsh, J. D., and Jantet, G. H. (1958), Brit. med. J., 2, 407. Lowbury, E. J., and Lilly, H. A. (1960). Ibid., 1, 1445.

Williams, R. E. O., Blowers, R., Garrod, L. P., and Shooter, R. A. (1960). Hospital Infection, Causes and Prevention, p. 71. Lloyd-Luke, London.

\title{
SILICONE SPRAYS IN PREVENTION AND TREATMENT OF DECUBITUS SKIN DISORDERS IN DOMICILIARY NURSING
}

BY

J. P. W. HUGHES, M.D., D.P.H.

Principal Medical Adviser, Albright and Wilson Ltd.

\section{G. S. WIGLEY, M.R.C.S., L.R.C.P., D.P.H. Deputy Medical Officer of Health, Middlesex County Council}

Silicone fluids have been incorporated into ointments and barrier creams since their properties became generally known. Their main uses have been as vehicles for medicaments (Laumanns, 1958) and to protect the skin against discharges such as around colostomy wounds, napkin areas in infants, and folds of skin macerated by intertrigo (Wigley, Calnan, Meara, and Seville, 1952). Smith, Day, and Zimmerman (1953) found a silicone cream more effective than other barrier creams against eczematogenous contact allergens. M. A. Cooke (personal communication, 1961) also found a delayed and reduced area of reaction in a procaine-sensitive patient by applying a silicone and methyl cellulose emulsion to the skin for four days prior to the application of $2 \%$ procaine, compared with control sites similarly treated with a standard barrier cream or left unprotected.

Silicone fluids were chosen because they are inert: they protect the skin and permit normal healing to take place (Morrow, 1954). They were found particularly valuable against aqueous systems whether from body discharges or in protecting the skin from outside contact, as in hydrotherapy (Accart, 1957).

Other workers (Bateman, 1956; James, 1956; Roberts, 1959) have used silicone creams in the prevention of decubitus ulcer, claiming not only that they were effective but that they also saved the nurses' time. Roberts and Williams (1957) first described silicone barrier creams in domiciliary nursing and found them so successful that they instituted them throughout the nursing services for which they were responsible.

Since nearly all the work on decubitus ulcers had been with silicone barrier creams, although Brusca (1956) and Roberts (1962a) had used a spray with success, we thought it might be valuable to compare the use of barrier creams and silicone sprays with the traditional method in domiciliary nursing.

\section{Materials and Methods}

Silicone fluids are linear polymers based on the siloxane $\left(\mathrm{R}_{2} \mathrm{SiO}\right)$ unit. The polymers can be of varying length, and as the molecular weight increases so does the viscosity. The reference numbers MS 200 and MS 555 which are used to describe the fluids we used are a commercial convenience. The B.P.C. designation for polydimethylsiloxane fluids suitable for pharmaceutical application is dimethicone, and these are available as MS 200 fluids. The repeating polymer unit is $\mathrm{Me}_{\mathbf{2}} \mathrm{SiO}$, and all the organic groups attached to the silicone are methyl groups. The fluid MS 555, which has both phenyl and methyl substituent groups in its molecule, has the unusual property among silicone fluids of being soluble in alcohol, while the dimethicone fluids are not. MS 555 fluid was used in two strengths, $2 \%$ and $5 \%$ in ethanol, and sprayed from "freon" (dichlorofluoromethane)-operated canisters: the two were distinguished by colour of the label only, and neither G. S. W., who directed the trial, nor the nurses knew which strength of silicone they used.

The Middlesex County Council organizes its homenursing service through ten local area committees. The superintendents of home nursing from the areas met us to discuss the nature and objects of the trial, and their co-operation was readily given. It was pointed out that if silicone sprays were as effective as more-established methods two advantages might accrue: first, saving of nursing-time, and, second, a spray might be used by the patients' relatives in domiciliary nursing in the nurse's absence, where a more difficult or more time-consuming method would either not be undertaken or be under- 
taken ineffectively. A detailed scheme was evolved with the advice of the superintendents.

Twelve nurses from each area took part in the trial and all were volunteers. Those who normally used the traditional toilet (soap, water, and powder, with or without an alcohol rub) continued with this treatment, which was termed the "orthodox" method. Those nurses who preferred to use a silicone cream continued with it. Others who were keen to try the sprays were allotted them and continued to use one or the other strength throughout. A standard procedure or a standard barrier cream was not insisted upon, since to do so might try the co-operation of the nurses, and the general practitioners for whom they worked, too far. Nurses were not directed into following a particular method; they were permitted to elect their own provided they followed it through the three-months trial. In this way it was hoped that bias due to enthusiasm would be eliminated. All cases where a skin disorder was already present were included in the trial, as were cases where the onset of such conditions seemed likely.

The superintendents held meetings with their nurses to make sure what was expected of them. The nurses were asked to record on a simple form the progress of each case. All patients who were receiving skin toilet were included: they were of both sexes, of a wide age range, and suffered from a variety of disorders. They were classified according to the condition of their skin at the start of the trial, and these fell into two broad groups of those with normal and those with abnormal skin. The numbers in each group were 101 and 91 respectively. We decided to exclude skin conditions which deteriorated within 48 hours of death, and these we called terminal cases, as we considered that deterioration was inevitable and the small number of deaths expected might by mischance all fall in one group. It transpired that their removal from the analyses did not affect the result.

Since patients were admitted to the trial over the whole of the three months and were included in the trial in every case where the treatment period exceeded 13 days, whether a patient was " cured " or " improved" may have depended on the length of time he had been under treatment. For that reason and also because of the small number of patients in the trial it was thought best to combine the two categories of "cured and improved" and compare them with the combined "no change and deteriorated" groups.

The results of this trial (Tables I and II) indicated that there might be an advantage in using a higher

Table I.-First Trial. Patients with Normal Skin on Entry into Trial

\begin{tabular}{|c|c|c|c|c|}
\hline \multirow{2}{*}{ Treatment } & & \multirow{2}{*}{$\begin{array}{l}\text { No. of } \\
\text { Patients }\end{array}$} & \multicolumn{2}{|c|}{ Deteriorated } \\
\hline & & & No. & $\%$ \\
\hline $\begin{array}{l}\text { Orthodox .. .. } \\
\text { Silicone cream } \\
\text { Silicone spray } 2 \% \\
\text { Silicone spray } 5 \%\end{array}$ & $\begin{array}{l}\cdots \\
\cdots \\
\cdots\end{array}$ & $\begin{array}{r}46 \\
9 \\
23 \\
23\end{array}$ & $\begin{array}{l}2 \\
3 \\
5 \\
5\end{array}$ & $\begin{array}{l}4 \\
33 \\
22 \\
22\end{array}$ \\
\hline Total & . & 101 & 15 & 15 \\
\hline
\end{tabular}

concentration of silicone. It was also evident that the alcohol in the spray caused cold and discomfort and might be responsible for causing deterioration in some cases. It was therefore decided to extend the trial, using $100 \%$ silicone sprays in freon-operated canisters. As solubility in ethanol was no longer a factor of importance, any of the silicone fluids could now be used, and the official B.P.C. preparation dimethicone (MS 200/350 centistokes fluid) was compared with the MS 555 fluid. The two trials ran for three months each, but in the second trial an initial shortage of the dimethicone-filled canisters meant that many more cases were treated with the MS 555 fluid.

The forms were completed by the nurses conscientiously and with an accuracy which indicated great interest on their part. Very few in the first trial had to be referred back to them for elucidation and none in the second. The forms were collected and transferred to punch cards (Copeland Chatterton) for analysis. The information on the basic record was checked by us jointly against the card before the analysis was made.

\section{Results of First Trial}

In the first trial a comparison was made of (1) orthodox, (2) silicone cream, (3) $2 \%$ MS 555 spray in ethanol, and (4) $5 \%$ MS 555 spray in ethanol.

\section{Patients with Normal Skin at Entry into Trial}

Table I shows the results of the four different methods. Nearly half the patients with normal skin at the start of the trial were treated by the orthodox method and all but two remained healthy. Those treated with silicones in any form did not do as well, since $24 \%$ developed some rash or other skin abnormality, though this was usually of a trivial nature. This was a surprising finding, because the workers referred to above had found silicones as effective as the orthodox method if not more so. The fact that nurses using the orthodox method included more patients with normal skins in the trial may indicate that they were more cautious in anticipating the possibility of breakdown: this would seem to be supported by the very low breakdown in this group.

\section{Patients with an Abnormal Skin on Entry to Trial}

Table II shows the results of the four different methods compared in patients with various skin conditions. Three categories of abnormal skin were defined : these were decubitus ulcer of any size, the pre-ulcer state (which was a familiar sign to the nurses), and a rash, whether specified as a urine rash or unspecified. There were 35 patients with ulcers (one of them terminal), 32 patients in a pre-ulcer state (with a second terminal case), and 24 patients with a rash. Silicones were not sprayed on the ulcers but were used to protect the surrounding intact but unhealthy skin. In all other conditions the silicones were sprayed directly on to the lesions.

Table II shows the results in cases and percentages. The two terminal cases (one in treatment group 1, and one in treatment group 4) have been removed from the analysis. It is immediately apparent that the $5 \%$ silicone spray is the most effective treatment, and there is little to choose between the other two silicone treatments and the orthodox method. We were not surprised that the stronger silicone spray was more effective than the weaker, because Roberts (1959) had found in silicone creams that a $20 \%$ cream was more effective than a $15 \%$ one (although curiously the $25 \%$ was less effective). It can be seen from Table II that the $5 \%$ spray was effective in 25 out of 30 cases $(83 \%)$, whereas the other treatments were effective in 35 out of 59 patients $(59 \%)$. The standard error of the difference between these two percentages is 9.5 , so that the percentage success of the $5 \%$ spray is greater than "the 
others" percentage success +2 S.E. (confidence limits $59 \pm 19=40-78$ ).

Since silicone fluids are generally inert the finding of some apparently positive healing action in the $5 \%$ MS 555 spray induced us to look into this question further. Brusca (1956) used 2\% silicone 555 fluid in $95 \%$ ethanol daily to spray the buttocks and backs of 41 bedridden incontinent senile patients and found it not only prevented the onset of dermatitis but cleared the skin of 26 patients in whom a dermatitis was already present. This is not necessarily proof that natural healing was hastened, and it might have occurred under an inert protective layer as with dimethicone or other silicone fluids. Roberts (1962b) described the use of a silicone aerosol as being effective in the prevention and treatment of bedsores. His aerosol, however, contained other ingredients which were intended to be the active agents in promoting healing. We knew of no other clinical evidence of a healing effect of MS 555 fluid, but it so happened that J. G. Feinberg (personal communication, 1961) was working on silicone fluids as vehicles for subcutaneous injections. He found that MS 555 fluid caused an extensive fibrosis when injected subcutaneously in the guinea-pig. All the other silicone fluids he used were inert, including dimethicone (MS 200/350): in these there was no reaction and the fluid remained unchanged in the tissues.

It seemed on the face of it that there was some positive therapeutic effect of MS 555 on the skin, and not merely a protective effect. The finding of this effect in the stronger MS 555 in ethanol spray made us look into the question further.

As dimethicone is the official B.P.C. preparation it was important to compare the two pure fluids in freonoperated canisters.

\section{Results in Second Trial}

In the second trial MS $555100 \%$ spray was compared with MS $200100 \%$ spray.

Patients with Normal Skin at Entry into Trial.-Only 18 cases with normal skin entered into the trial, and, owing to delays in obtaining the MS 200 spray, only threo healthy skins were treated with it. One of the three deteriorated while the other two remained healthy. There were 15 healthy skins treated with MS 555 fluid, and of these 14 remained healthy and one deteriorated.
The numbers are small, but such evidence as there is indicates that pure MS 555 fluid appears to have an excellent protective effect on normal skin.

Patients with an Abnormal Skin at Entry into Trial.There were 60 patients in this series, of whom 42 were treated with MS 555 and 18 with MS 200. We grouped all skin conditions (decubitus ulcer, per-ulcer state, and rashes) and both sexes together and compared the effectiveness of the two silicones. Only $55 \%$ of the MS 200 series were cured or improved compared with $81 \%$ of the MS 555 series. The standard of error of the difference between these percentages is 13 , and $55 \%$ +2 S.E. $=81$, so that the difference is of borderline significance at the $5 \%$ level. In established decubitus ulcer there is no evidence that MS 555 is more effective than MS 200. With the former, 14 were "cured and improved " and 6 showed "no change and deteriorated" against 8 and 3 respectively for MS 200. This is to be expected, for the ulcers themselves were treated by other means. The beneficial effect is on diseased skin which has not yet ulcerated: $20 \mathrm{C}+\mathrm{I}$ and $2 \mathrm{NC}+\mathrm{D}$ for MS 555 against $2 \mathrm{C}+\mathrm{I}$ and $5 \mathrm{NC}+\mathrm{D}$ for MS 200. The standard error of the difference between these two percentages is 18 , so that the difference is over three times the S.E.

\section{Discussion}

The evidence from either of the two trials is not in itself very strong, but the two together, although they cannot be directly added (because only the MS 555 was used in the firsi trial), make us more confident that MS 555 has a positive healing action.

In order to look for bias we examined the characteristics of the two groups treated by the various methods. Mention has already been made of the skew distribution of those with healthy skins who were treated by the orthodox method in the first trial. In the second trial the groups were analysed for age, sex, disease code, and incontinence (urinary, faecal, or both). For some unexplained reason proportionately more women were treated with MS 200 than MS 555, but there was no difference in age, incontinence, or the types of disease from which these patients suffered.

There was no difference in the percentage success of the $5 \%$ MS 555 silicone spray compared with the $100 \%$, but the pure spray is far more acceptable to the

TABLE II.-First Trial. Patients with a Skin Condition on Entry into Trial

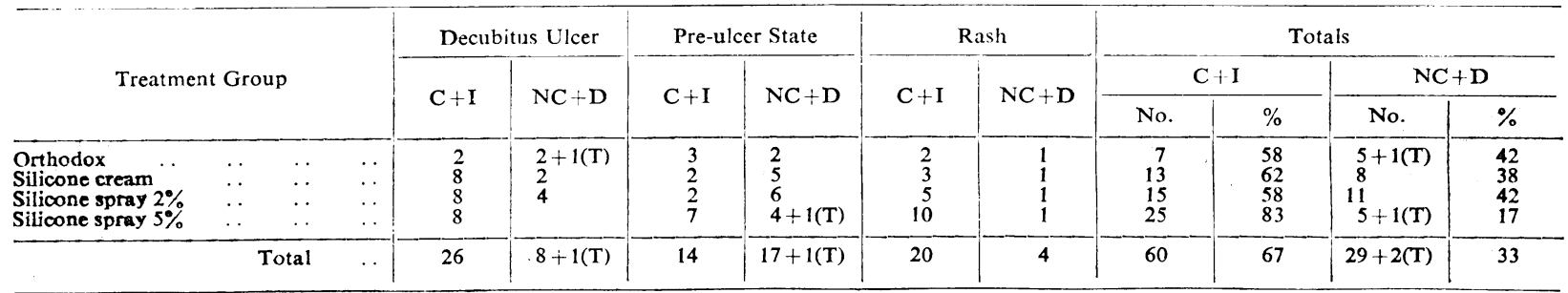

$C+I=$ Cared and improved. $T=$ Terminal. $\quad \mathrm{NC}+\mathrm{D}=$ No change and deteriorated. Terminal cases are excluded from the percentage figures.

TABLE III.-Second Trial. Patients with a Skin Condition on Entry into Trial

\begin{tabular}{|c|c|c|c|c|c|c|c|c|c|c|c|c|c|c|}
\hline \multirow{3}{*}{\multicolumn{4}{|c|}{ Treatment Group }} & & \multicolumn{2}{|c|}{ Decubitus Ulcer } & \multicolumn{2}{|c|}{ Pre-ulcer State } & \multicolumn{2}{|c|}{ Rash } & \multicolumn{4}{|c|}{ Totals } \\
\hline & & & & & \multirow{2}{*}{$\mathrm{C}+\mathrm{I}$} & \multirow{2}{*}{$\mathrm{NC}+\mathrm{D}$} & \multirow{2}{*}{$\mathrm{C}+\mathrm{I}$} & \multirow{2}{*}{$\mathrm{NC}+\mathrm{D}$} & \multirow{2}{*}{$\mathrm{C}+\mathrm{I}$} & \multirow{2}{*}{$\mathrm{NC}+\mathrm{D}$} & \multicolumn{2}{|c|}{$C+I$} & \multicolumn{2}{|c|}{$\mathrm{NC}+\mathrm{D}$} \\
\hline & & & & & & & & & & & No. & $\%$ & No. & $\%$ \\
\hline \multirow[t]{2}{*}{$\begin{array}{l}\text { MS } 200 \\
\text { MS } 555\end{array}$} & $\begin{array}{l}\cdots \\
\cdots\end{array}$ & $\begin{array}{l}\ldots \\
\cdots\end{array}$ & $\begin{array}{l}\ldots \\
\cdots\end{array}$ & $\begin{array}{l}\ldots \\
\cdots\end{array}$ & $\begin{array}{r}8 \\
14\end{array}$ & $\begin{array}{l}3 \\
6\end{array}$ & $\overline{6}$ & $\begin{array}{l}4 \\
1\end{array}$ & $\begin{array}{r}2 \\
14\end{array}$ & $\begin{array}{l}1 \\
1\end{array}$ & $\begin{array}{l}10 \\
34\end{array}$ & $\begin{array}{l}55 \\
81\end{array}$ & $\begin{array}{l}8 \\
8\end{array}$ & $\begin{array}{l}45 \\
19\end{array}$ \\
\hline & & & Total & . & 22 & 9 & 6 & 5 & 16 & 2 & 44 & 73 & 16 & 27 \\
\hline
\end{tabular}


patient, and is more likely, therefore, to be used in domiciliary nursing in the nurse's absence.

An adequate layer of silicone on the skin is probably more economically obtained by using $100 \%$ silicone, for it is more easily seen and the silicone in alcohol tends to run off the patient's back during spraying, carrying the silicone to areas where it is not required. Alcohol is also uncomfortably cold, and we had one patient who refused to continue with the treatment: when we tried the spray on ourselves we had much sympathy for her. The spraying technique can be taught by the nurse to dullest relative in a few moments.

\section{Summary}

Two trials to evaluate the use of silicone sprays in the prevention and treatment of decubitus skin conditions in domiciliary nursing were undertaken in 1961. In the first trial it was found that with patients having normal skin the traditional method used in hospitals for generations was the most effective, but with patients with a skin condition a $5 \%$ MS 555 silicone fluid in ethanol was significantly more effective than all other treatments combined (including a 2\% MS 555 in ethanol spray). Other evidence that MS 555 fluid is not as inert as other silicone fluids led us to a second trial comparing $100 \%$ MS 555 with 100\% dimethicone (MS 200 fluid) in freon-operated canisters. The pure MS 555 fluid effectively maintained normal skin in good condition in 14 out of 15 patients and was far more effective in treating established skin conditions (other than areas of actual ulceration, which were not sprayed with either silicone). The pure fluid is probably more economical in use, much more comfortable to the patient than silicone in alcohol sprays, takes only a few seconds to administer, and can more easily be continued by the relatives in the nurse's absence.

It is concluded that pure MS 555 spray is the method of choice in the prevention and treatment of decubitus skin disorders.

We acknowledge the loyal and conscientious work of all the nurses, too many to mention by name, who made this trial possible, and the helpful co-operation of the general practitioners in charge of the patients. Our thanks are also due to Midland Silicones Limited for the supply of silicones; to Mr. R. L. Bass of that company for chemical advice ; and to Messrs. Lactagol Ltd.. who supplied us with the complete canisters.

\section{REFERENCES}

Accart, R. (1957). J. Méd. Lyon, 38, 727.

\begin{tabular}{l} 
Accart, R. (1957). J. Méd. Lyon, 38, 727. \\
Bateman, F. J. A. (1956). Brit. med. J., 1, 554. \\
Brusca, D. D. (1956). N.Y. St. J. Med., 56, 894. \\
James, M. . (1956). Nursing Mirror, November 16, p. 482. \\
Laumanns, M. (1958). Ther. d. Gegenw., 97, 109. \\
Morrow, G. (1954). Calif. Med., 80, 21. \\
Roberts, G. W. (1959). Lancet, 1, 1207. \\
(1962a). Ibid., 1, 110. \\
\hline (1962b). Nursing Mirror, February 2, p. 347. \\
and Williams, F. M. (1957). Lancet, 1, 1094. \\
Smith, C. C., Day, T. L., and Zimmerman, E. H. (1953). J. \\
invest. Derm., 21, 111. \\
Wigley, J. E. M., Calnan, C. D.. Meara, R. H., and Seville, \\
R. H. (1952). Practitioner, 169, 354. \\
\hline
\end{tabular}

A letter "received by me some 70 years ago from Miss Florence Nightingale" has been left by Colonel Sir William Coates, the physician of Manchester, who died last January aged 101 , to his son, Colonel James Coates, "in gratitude for his untiring kindness night and day showed to me in my illnosses." Sir William left $£ 63,919$ ( $£ 63.160$ net ; duty $£ 30,470$ )

\section{ANOTHER HYPOTENSIVE AGENT- METHYLDOPA}

BY

DENIS DALEY, M.B., B.Ch.

AND

BYRON EVANS, M.D., F.R.C.P.

United Cardiff Hospitals

There is as yet no ideal drug available for the lifelong treatment of patients with essential or irremediable secondary hypertension. Such a hypotensive agent should have a consistently reliable effect when given by the mouth and there should be no side-effects. After long-continued use tolerance to the drug should not occur, and the patient should feel well and thus encouraged to continue with treatment. In search of this ideal drug the output of new and improved hypotensive agents is so rapid that there is barely time to evaluate one before another becomes available. During the last six months observations have been made on the clinical effects of methyldopa ("aldomet"). It is probable that in the near future it will be combined with other hypotensive agents to produce a better response than when used alone, but the purpose of this investigation was to determine whether methyldopa given alone was of value in the treatment of hypertension.

The mode of action of methyldopa (alpha-methyl-3,4dihydroxy-1-phenylalanine) in lowering blood-pressure is not fully understood. Several investigators (Sourkes, 1954 ; Smith, 1959 ; Oates et al., 1960) have shown that the drug inhibits the decarboxylation of dopa and other amino-acids and thus diminishes the production of noradrenaline and serotonin in the brain and other tissues. It has since been suggested by Gillespie $e t$ al. (1962) that because methyldopa has a sedative as well as a hypotensive action, properties not shared by other decarboxylating agents, the site of action may well be central. These same authors have shown that $15 \%$ to $30 \%$ of an oral dose is absorbed in the gastro-intestinal tract and that the drug is excreted largely unaltered in the urine. The blood levels reach a maximum in two to four hours after administration and fall rapidly over the succeeding four to six hours.

\section{Material and Methods}

Up to the present time five female and 15 male hypertensive patients, whose ages varied from 36 to 61 years, were treated with methyldopa for periods of four weeks to six months. Of the 20 patients, 16 were regarded as having primary or essential hypertension, but it must be emphasized that renal arteriography was not performed in any of them and thus a renal cause was not definitely excluded. All the patients had thickened peripheral arterial walls, fundal changes, and electrocardiographic evidence of left ventricular hypertrophy ; almost all of them had clinical and radiographic evidence of left ventricular hypertrophy ; and some had albuminuria (Table I). All warranted treatment with a hypotensive drug. In addition to the clinical features the initial blood-urea level is shown in Table I because it is an estimation of such prognostic importance. 